\title{
Commentary: Cannulation alternatives for acute type I aortic dissection: Does this constitute a conundrum?
}

\author{
Alan M. Speir, MD
}

\author{
From the Department of Cardiac Surgery, Inova Heart and Vascular Institute, Falls Church, Va. \\ Disclosures: Author has nothing to disclose with regard to commercial support. \\ Received for publication Dec 3, 2018; accepted for publication Dec 4, 2018; available ahead of print Jan 17, 2019. \\ Address for reprints: Alan M. Speir, MD, Cardiac Surgery, Inova Heart and Vascular Institute, 3300 Gallows Rd, \\ Falls Church, VA 22042 (E-mail: alan.speir@inova.org). \\ J Thorac Cardiovasc Surg 2019;158:35-6 \\ $0022-5223 / \$ 36.00$ \\ Copyright $(2018$ by The American Association for Thoracic Surgery \\ https://doi.org/10.1016/j.jtcvs.2018.12.016
}

Cannulation techniques for surgical intervention on the thoracic aorta requiring cardiopulmonary bypass has experienced quite an evolution since Lellehei first reported the use of femoral cannulation. ${ }^{1}$ As a result of the early complications associated with femoral cannulation for cardiac surgery, mainly related to arterial dissection and retrograde cerebral and visceral emboli, ${ }^{2}$ this method was soon replaced by direct cannulation of the ascending aorta in the main surgical field and, subsequently, the axillary artery in the presence of ascending aortic pathology. In this issue of the Journal, ${ }^{3}$ a single-center retrospective review of arterial cannulation techniques in aortic dissection type $\mathrm{A}$ (ADA) is presented. In total, 584 patients presenting with ADA were surgically treated with either direct aortic, femoral, or axillary cannulation. The results were quite credible in keeping with what we've come to expect from this high-volume aortic program. Despite the laudable surgical outcomes, however, there are several questions that still remain from their analysis.

The authors submit that central ascending aortic cannulation in patients with ADA can be used as safely as axillary or femoral cannulation. The technical details of such access to the true lumen was well described, illustrated, and supported by the accompanying video. The reality remains, however, that although this approach may be safe and reproducible in this center with a large experience in this technique, can this approach be readily adopted by centers with less experience with ADA? Moreover, for the surgical group with less expertise with acute dissection and the necessary skills in echocardiography that is critical to the success of acquisition of the true lumen, this surgical option may remain elusive despite the stated advantages. For that reason, is there enough evidence presented to motivate adoption by such centers from the standard of axillary cannulation to the direct aortic approach?

Of note was that retrograde cerebral perfusion (RCP) was "the preferred method of cerebral perfusion" in both the aortic and the femoral cannulation group. This cerebral protection method accounted for $83 \%$ of the patients analyzed. The routine use of this adjunctive technique for cerebral

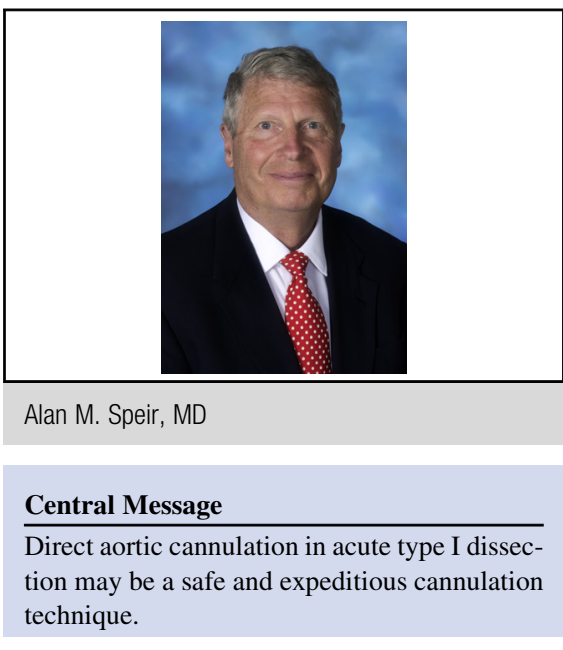

See Article page 27.

perfusion is surprising, given the clinical randomized trials that have revealed no evidence of cerebral metabolic, neurologic, or neuropsychological outcome benefit of $\mathrm{RCP}^{4,5}$ Despite this perceived limitation, there was no statistical difference in their reported procedure-related and/or dissection-related stroke rate. This may have been as much related to the depth of hypothermia than the use of RCP; however, the temperature level was not stated in the manuscript.

Although the authors have rationalized the use of the various cannulation techniques in ADA based on preoperative clinical status, site of intimal tear, and extent of dissection particularly with involvement of the brachiocephalic vessels, the ability to extract the surgical indication for each cannulation option remains a conundrum. The adoption of each of the 3 cannulation options may ultimately be based more on surgeon comfort and technical experience than the proposed usefulness of a newer, uncommon direct surgical approach. The usefulness of the direct aortic approach in ADA should, however, not be discounted, and an acquired level of familiarity with this option may prove quite useful particularly in the urgent or emergent clinical setting.

\section{References}

1. Lillehei CW. Use of median sternotomy with femoral artery cannulation in open cardiac surgery. Surg Gynecol Obstet. 1959;108:706-14.

2. Magner JB. Complications of aortic cannulation for open-heart surgery. Thorax. $1971 ; 26: 172-3$. 
3. Kreibich M, Rylski B, Bavaria JE, Brown CR, Branchett E, Vallabhajosyula P, et al. Outcome after aortic, axillary, or femoral cannulation for acute type A aortic dissection. J Thorac Cardiovasc Surg. 2019;158:27-34.

4. Bonser R, Wong C, Harrington D, Pagano D, Wilkes M, Clutton-Brock T, et al. Failure of retrograde cerebral perfusion to attenuate metabolic changes associated with hypothermic circulatory arrest. J Thorac Cardiovasc Surg 2002;123:943-50.

5. Harrington D, Bonser M, Moss A, Heafield M, Riddoch M, Bonser R. Neuropsychometric outcome following aortic arch surgery: a prospective randomised trial of retrograde cerebral perfusion. J Thorac Cardiovasc Surg. 2003;126:638-44. 